\title{
Effect of the Dry-Cured Fermented Sausage "Salchichón" Processing with a Selected Lactobacillus sakei in Listeria monocytogenes and Microbial Population
}

\author{
Irene Martín (D), Alicia Rodríguez, Lourdes Sánchez-Montero, Patricia Padilla and Juan J. Córdoba *D
}

check for

updates

Citation: Martín, I.; Rodríguez, A.; Sánchez-Montero, L.; Padilla, P.;

Córdoba, J.J. Effect of the Dry-Cured Fermented Sausage "Salchichón"

Processing with a Selected

Lactobacillus sakei in Listeria

monocytogenes and Microbial

Population. Foods 2021, 10, 856.

https://doi.org/10.3390/foods10040856

Academic Editor:

Andreas Kimon Karatzas

Received: 28 March 2021

Accepted: 13 April 2021

Published: 15 April 2021

Publisher's Note: MDPI stays neutra with regard to jurisdictional claims in published maps and institutional affiliations.

Copyright: (C) 2021 by the authors. Licensee MDPI, Basel, Switzerland. This article is an open access article distributed under the terms and conditions of the Creative Commons Attribution (CC BY) license (https:// creativecommons.org/licenses/by/ $4.0 /)$.
Food Hygiene and Safety, Meat and Meat Products Research Institute, Faculty of Veterinary Science, University of Extremadura, Avda. de las Ciencias. s/n, 10003 Cáceres, Spain; iremartint@unex.es (I.M.); aliciarj@unex.es (A.R.); lourdessv@unex.es (L.S.-M.); patriciapt@unex.es (P.P.)

* Correspondence: jcordoba@unex.es

Abstract: In the present work, the effect of processing of dry-cured fermented sausage "salchichón" spiked with the selected Lactobacillus sakei 205 was challenge-tested with low and high levels of L. monocytogenes. The evolution of the natural microbial population throughout the "salchichón" ripening was also evaluated. For this, a total of 150 "salchichón" were elaborated and divided into six equal cases which were inoculated with different levels of L. monocytogenes, and L. sakei 205. Afterwards, sausages were ripened for 90 days according to a typical industrial process. Moisture content $(\%)$ and water activity $\left(\mathrm{a}_{\mathrm{w}}\right)$ decreased throughout the ripening up to values around $26 \%$ and 0.78 , respectively. No differences for moisture content, $\mathrm{a}_{\mathrm{w}}, \mathrm{pH}, \mathrm{NaCl}$ and nitrite concentration were observed between the analyzed cases. Lactic acid bacteria counts in the L. sakei 205 inoculated cases were always higher than $6 \log \mathrm{CFU} \mathrm{g}{ }^{-1}$ during ripening. Enterobacteriaceae counts were reduced during ripening until non-detectable levels at the end of processing. Reductions in L. monocytogenes counts ranged from 1.6 to $2.2 \mathrm{log}$ CFU g ${ }^{-1}$; therefore, the processing of "salchichón" itself did not allow the growth of this pathogen. Reduction in L. monocytogenes was significantly higher in the cases inoculated with L. sakei 205.

Keywords: L. monocytogenes reduction; dry-cured fermented sausages; L. sakei; challenge test

\section{Introduction}

Dry-cured fermented sausages are Mediterranean products that are widely consumed in Spain and well known in international markets [1,2]. Among the Spanish dry-cured fermented sausages, "salchichón" is a typical dry-cured fermented sausage classed as a ready-to-eat (RTE) food that is manufactured with traditional technologies without adding starter cultures [3]. This product is usually made from comminuted meat and fat, mixed with salt and other spices, and filled into casings, before their ripening in drying chambers, at temperature and relative humidity $(\mathrm{RH})$ conditions that may vary between 7 and $14{ }^{\circ} \mathrm{C}$, and 80 and $85 \%$, respectively $[4,5]$. At these conditions, a decrease in water activity $\left(\mathrm{a}_{\mathrm{w}}\right)$ values below 0.90 and a slight reduction in $\mathrm{pH}$ to levels ranging from 5.4 to 6.0 have usually been reported for this kind of meat product [6,7].

The food-handling involved in the manufacture of "salchichón" increases the risk of microbial contamination, with Listeria monocytogenes being the most hazardous pathogenic microorganism in this RTE product. L. monocytogenes is the causative agent of listeriosis, one of the most serious foodborne diseases caused mainly by food consumption [8]. Dry-cured fermented sausages are considered products with low risk for foodborne listeriosis [9,10]; however, the presence of this pathogenic bacterium has been reported in ripened sausages [11-13], and in some cases, it has even been involved in listeriosis outbreaks $[14,15]$. 
In the European Union (EU), the food safety criteria for L. monocytogenes in RTE food products have been published in the Regulation (CE) 2073/2005 [16] amended by Regulation (CE) 1441/2007 [17]. This regulation set a maximum level of $100 \mathrm{CFU} \mathrm{g}^{-1}$ for L. monocytogenes in RTE foods throughout their shelf life. However, it has been found that dry-cured fermented sausages contaminated by L. monocytogenes at levels higher than $100 \mathrm{CFU} \mathrm{g}^{-1}$ are consumed without any further heat treatment in the EU. Thus, the development of L. monocytogenes in this RTE meat product should be considered a great public health concern [13].

In order to minimize the risk that the presence of L. monocytogenes implies in drycured fermented sausages, the implementation of a process addressing the survival of this pathogenic bacteria throughout the manufacturing procedure is of great importance [18]. Thus, reducing or eliminating L. monocytogenes from meat products is a real challenge for the meat industry and food safety authorities.

There are few references in the literature of a challenge test to evaluate the effect of processing of "salchichón" in the growth/inactivation of L. monocytogenes. Thus, it is not clear if L. monocytogenes can be diminished throughout the processing of this product. Different studies have indicated that this pathogen could survive during the dry-cured fermented sausage's manufacturing and may not be completely eliminated [19], and in some cases, the growth of this microorganism was reported during ripening [20].

In the evaluation of the growth/inactivation of L. monocytogenes throughout the processing of "salchichón", the effect of lactic acid bacteria (LAB) should be considered because selected LAB strains have demonstrated antimicrobial effect against this pathogenic bacterium [21,22]. Among LAB, Lactobacillus sakei has a technological use in the preservation of several dry-cured fermented sausages due to its capacity to produce organic acids, hydrogen peroxide, and bacteriocins [23]. In fact, L. sakei has shown protective antimicrobial effect against both pathogenic and spoiler microorganisms in meat products [24,25].

In addition to the evaluation growth/inactivation of L. monocytogenes, the effect of processing of "salchichón" on the evolution of a natural microbial population should be determined, because unusual development of some microbial groups may lead to irregular microbial quality of the sausages and even spoilage during ripening. For example, growth of some Enterobacteriaceae strains throughout ripening in dry-cured meat products has been reported [26], which may reduce the microbiological quality of the sausage pieces.

With the aim of evaluating potential food safety implications, "salchichón" spiked with selected strains of L. sakei was challenge-tested with low and high levels of L. monocytogenes. In addition, the effect of dry-cured fermented sausage "salchichón" processing on the evolution of the natural microbial population of this product was evaluated.

\section{Materials and Methods}

\subsection{Microbial Cultures}

The strain L. sakei 205 from the Food Hygiene and Safety Collection at the University of Extremadura was used for the inoculation of "salchichón", with LAB as a protective culture. This strain was isolated from traditional dry-cured fermented sausages and selected by its antagonist activity against L. monocytogenes in agar "salchichón" (unpublished data). To prepare the inoculum of L. sakei 205, $100 \mu \mathrm{L}$ of a stock culture (stored in brain heart infusion (BHI) broth (Conda, Spain) containing $20 \%(w / v)$ glycerol at $-80{ }^{\circ} \mathrm{C}$ ) were inoculated onto $10 \mathrm{~mL}$ of de Man-Rogosa-Sharpe (MRS) broth (Fisher Bioreagents, Belgium) and incubated for $48 \mathrm{~h}$ at $30{ }^{\circ} \mathrm{C}$. At the end of the incubation, $\approx 8.0 \log \mathrm{CFU} \mathrm{mL} \mathrm{m}^{-1}$ cells were obtained and an aliquot of this was diluted in $1 \%(w / v)$ peptone water (Conda, Spain) to reach a final concentration of approximately $6.0 \log \mathrm{CFU} \mathrm{mL}{ }^{-1}$. Then, the culture was centrifuged at $10,000 \times g$ for $5 \mathrm{~min}$, and the supernatant was discarded. The sediment was then washed and resuspended in phosphate-buffered saline (PBS) and used for the inoculation of the "salchichón" mix before stuffing. To determine the final concentration (CFU mL ${ }^{-1}$ ) of $L$. sakei 205 in PBS in order to adjust the level of inoculation, serial dilutions in $1 \%(w / v)$ peptone water were inoculated onto MRS agar (Oxoid, UK) and incubated anaerobically at 
$30{ }^{\circ} \mathrm{C}$ for $72 \mathrm{~h}$. In addition, initial levels of LAB on the sausages at day 0 of processing were determined as described previously.

For the inoculation of the "salchichón" with L. monocytogenes, strain S7-2 (serotype 4b) belonging to National Institute of Agricultural and Food Research and Technology (INIA) collection (Madrid, Spain) was used. To prepare the L. monocytogenes inoculum, $100 \mu \mathrm{L}$ of a stock culture (stored in BHI broth containing $20 \%(w / v)$ glycerol at $-80{ }^{\circ} \mathrm{C}$ ) were transferred to $10 \mathrm{~mL}$ BHI broth and incubated for $24 \mathrm{~h}$ at $37^{\circ} \mathrm{C}$. A total of $100 \mu \mathrm{L}$ of such culture were then transferred to a second tube of $10 \mathrm{~mL} \mathrm{BHI}$ and incubated overnight at $37^{\circ} \mathrm{C}$. At the end of the incubation period, $\approx 8.0 \log \mathrm{CFU} \mathrm{mL}{ }^{-1}$ cells were obtained and aliquots of this were diluted to reach final concentrations of approximately $7.0 \log$ CFU mL $\mathrm{mL}^{-1}$ and $4.0 \log$ CFU mL $\mathrm{mL}^{-1}$. Then, the cultures were centrifuged at $10,000 \times g$ for $5 \mathrm{~min}$, the supernatants discarded, and the sediments were washed and resuspended in PBS and used for the inoculation of the "salchichón" mix before stuffing. To verify the levels of inoculation, serial dilutions were inoculated onto Chromagar ${ }^{\mathrm{TM}}$ Listeria agar plates and incubated at $37^{\circ} \mathrm{C}$ for $48 \mathrm{~h}$. In addition, the real initial levels (CFU g ${ }^{-1}$ ) of $L$. monocytogenes on the sausages were determined at day 0 of processing.

\subsection{Preparation of Dry Fermented Sausages "Salchichón"}

The mixture used for the manufacture of dry fermented sausages "salchichón" was purchased from a meat company in the Extremadura region (Cáceres) and its composition consisted of minced Iberian pork meat (90\%) and Iberian pig fatback (7\%), with an addition of $\mathrm{NaCl}(1.8 \%)$, cane sugar $(0,4 \%)$, potassium nitrate $(120 \mathrm{ppm})$, sodium nitrite $(100 \mathrm{ppm})$, black paper and spices. This mixture was transported in refrigerated conditions $\left(<2{ }^{\circ} \mathrm{C}\right)$ from the company to the meat pilot plant located at the Faculty of Veterinary of the University of Extremadura in order to prepare the sausages. Then, the mixture was divided into six equal cases of $10 \mathrm{~kg}$ each for the inoculation: (1) B (inoculated only with L. sakei at $\approx 6 \log$ CFU g ${ }^{-1}$ ); (2) LI (inoculated with L. monocytogenes at $\approx 4 \log \mathrm{CFU} \mathrm{g}^{-1}$ ); (3) $\mathrm{LI}+\mathrm{LAB}$ (inoculated with L. monocytogenes at $\approx 4 \log \mathrm{CFU} \mathrm{g}^{-1}$ combined with L. sakei at $\approx 6 \log \mathrm{CFU} \mathrm{g}{ }^{-1}$ ); (4) HI (inoculated with L. monocytogenes at $\approx 7 \log \mathrm{CFU} \mathrm{g}^{-1}$ ); (5) $\mathrm{HI}+\mathrm{LAB}$ (inoculated with L. monocytogenes at $\approx 7 \log \mathrm{CFU} \mathrm{g^{-1 }}$ combined with $L$. sakei at $\approx 6 \log \mathrm{CFU} \mathrm{g}{ }^{-1}$ ); and (6) C (uninoculated control).

In all cases, except in $C$, respective microorganism inocula were adjusted and prepared to be resuspended in a total volume of $150 \mathrm{~mL}$ of PBS (as described in Section 2.1) that were added to the ingredients and mixed with an automatic kneader, that was cleaned and sanitized between cases. In the case of C, $150 \mathrm{~mL}$ of sterilized PBS were added instead of the bacterium inocula.

The meat dough of each case was stuffed into regenerated collagen casings $(40 \mathrm{~mm}$ in diameter) supplied by Viscofan (Navarra, Spain). The final weight of each sausage was approximately $500 \mathrm{~g}$. The sausages obtained were ripened in controlled drying chambers at the Faculty of Veterinary Science of the University of Extremadura according to the industrial traditional conditions of "salchichón": $5^{\circ} \mathrm{C}$ at $85 \%$ relative humidity (RH) for 3 days, then $7{ }^{\circ} \mathrm{C}$ and $80 \% \mathrm{RH}$ for the 17 days, $9{ }^{\circ} \mathrm{C}$ and $75 \% \mathrm{RH}$ for 10 days, and finally, the sausages were kept at $12{ }^{\circ} \mathrm{C}$ and $70 \% \mathrm{RH}$ to reach 90 days of ripening.

Five sausages of each case were taken at $0,15,30,60$, and 90 days of the ripening time for microbiological and physicochemical analysis. Before analysis, casings were aseptically removed in a laminar flow cabinet (Telstar, Spain). The experiment, consisting of 6 different cases, 5 sampling times, and 5 different analyzed sausages for each case and sampling time, was evaluated once, according to the European Union Reference Laboratory Technical Guidance Document for conducting shelf-life studies on L. monocytogenes in RTE foods (such as "salchichón") where no growth or the growth probability of this pathogen is $\leq 10 \%$ [27]. 


\subsection{Microbiological Analysis}

2.3.1. Confirmation of Absence on L. monocytogenes Contamination in Control

Control $\mathrm{C}$ was tested to confirm the absence of natural contamination of L. monocytogenes. For this, $25 \mathrm{~g}$ of each of the 5 sausages were taken at every sampling time and evaluated for the presence or absence of this pathogen according to ISO 11290-1 (International Organization for Standardization [28]).

\subsubsection{Estimation of Microbiological Levels}

For the remaining microbiological analysis, $10 \mathrm{~g}$ of each of the 5 sausages were sampled at every sampling time, mixed with $90 \mathrm{~mL}$ of $1 \%(w / v)$ peptone water, and homogenized in a Stomacher machine (Seward, model 400 Circulator, West Sussex. UK) at $300 \mathrm{rpm}$ for $1 \mathrm{~min}$. Decimal serial dilutions were subsequently carried out in $1 \%(w / v)$ of peptone water, and then $100 \mu \mathrm{L}$ of the cell suspensions were spread onto the surface of different agar plates according to the microbial group analyzed.

In all the inoculated cases with L. monocytogenes (LI, LI+LAB, HI, and HI+LAB), viable counts of this pathogen were enumerated on CHROMagar ${ }^{\mathrm{TM}}$ Listeria Chromogenic media (CH-L, Scharlab, Barcelona, Spain) in duplicate. Each plate was seeded with $0.1 \mathrm{~mL}$, incubated at $37{ }^{\circ} \mathrm{C}$ for 24 and $48 \mathrm{~h}$. After the incubation period, the characteristic $L$. monocytogenes colonies, green colonies with a surrounded opaque halo, were counted.

In all cases, 5 groups of microorganisms were determined by using different culture media: the total viable microorganism counts on plate count agar (PCA; Conda Spain), LAB in MRS agar, Enterobacteriaceae on Violet Red Bile Glucose agar (VRBG, Conda, Spain), Staphylococci in Mannitol salt agar (MSA; Oxoid, UK) and mold and yeast counts on malt extract agar (MEA; $20 \mathrm{~g} / \mathrm{L}$ of malt extract (Scharlab, Spain), $1 \mathrm{~g} / \mathrm{L}$ of peptone water, $20 \mathrm{~g} / \mathrm{L}$ of D (+) glucose monohydrate (Scharlab, Spain), bacto agar $20 \mathrm{~g} / \mathrm{L}$ (Scharlab, Spain). All the above inoculated media were incubated at $30^{\circ} \mathrm{C}$ for $48 \mathrm{~h}$, except MEA and VRBG, which were cultured at $25^{\circ} \mathrm{C}$ for 5 days and $37^{\circ} \mathrm{C}$ for $24 \mathrm{~h}$, respectively.

\subsubsection{Evaluation of Implantation of L. sakei 205}

In addition, to evaluate the implantation of $L$. sakei 205 , MRS plates at the last sampling time (90 days) of L. sakei 205 inoculated cases were taken, and $50 \%$ of the characteristic $\mathrm{LAB}$ colonies were randomly isolated and inoculated in MRS broth and streaked on fresh MRS agar plates and incubated at $37^{\circ} \mathrm{C}$. The cultures were sub-cultured to obtain pure cultures. Pure cultures were maintained in a sterilized MRS broth and kept at $-20^{\circ} \mathrm{C}$ until characterization by molecular analysis. This procedure was also followed to evaluate LAB colonies on MRS plates in case $C$ at day 90 of ripening to confirm the absence of $L$. sakei 205. The identification of the LAB strains was performed by sequencing analysis of the $16 \mathrm{~S}$ rRNA region according to the methodology proposed by Walter et al. [29], and PFGE analysis of the DNA with the restriction NotI and SgsI enzymes (Thermo Fisher Scientific, Waltham, MA., USA) following procedures previously described by Alía et al. [30].

\subsection{Physicochemical Analysis}

All the analyses for determination of the physicochemical characteristics of the sausages were made in quintuplicates in those cases in which L. monocytogenes was not inoculated (B and C).

\subsubsection{Water Activity Determination}

The $\mathrm{a}_{\mathrm{w}}$ of dry fermented sausages "salchichón" was determined at $25^{\circ} \mathrm{C}$ by using a Novasina Lab Master Water activity meter model AW SPRINT-TH 300 (Novasina AG, Switzerland). Calibration was performed by using several saturated solutions of known $\mathrm{a}_{\mathrm{w}}$.

\subsubsection{Moisture Content Determination}

Moisture content was determined following the official methods of the Association of Official Analytical Chemists [31]. This parameter was determined gravimetrically. 


\subsection{3. $\mathrm{pH}$ Determination}

The $\mathrm{pH}$ was measured with a $\mathrm{pH}$-meter (Model 340, Mettler-Toledo GmbH, Greifensee, Switzerland) that was calibrated with 3 different standard $\mathrm{pH}$ solutions (4.0, 7.0 and 9.25). The $\mathrm{pH}$ was determined after homogenizing $3 \mathrm{~g}$ of each sample with $27 \mathrm{~mL}$ of distilled water for $30 \mathrm{~s}$ using a homogenizer.

\subsubsection{Sodium Chloride Determination}

$\mathrm{NaCl}$ was determined in duplicate for each of the 5 dry-cured sausages of each case at the end of the ripening period using the Volhard method [32].

\subsubsection{Nitrite Determination}

Nitrite content was determined in each of the 5 dry-cured sausages of each case at the end of the ripening period according to the method described by AOAC (2005) [33]. Measurement of residual nitrite was spectrophotometrically conducted from pinkish dye produced by coupling sulfanilamide with NED dihydrochloride. A calibration curve was obtained by diluting the standard solution $\left(100 \mathrm{mg} / 1 \mathrm{NaNO}_{2}\right)$ with distilled water to cover a concentration range from 0.1 to $0.8 \mathrm{mg} / 1 \mathrm{NaNO}_{2}$. The residual nitrite content was calculated using a standard curve of nitrite solution as $\mathrm{mg}$ nitrite per $\mathrm{kg}$ sample.

\subsection{Statistical Analyses}

The statistical treatment was carried out using the software IBM SPSS Statistic version 20 (IBM, New York, NY, USA). For the statistical analysis of the data, different cases and days of ripening were used as independent variables. The counts $\left(\log C F U g^{-1}\right), a_{w}$, $\mathrm{pH}$, moisture content, sodium chloride, and nitrite values were analyzed as dependent variables. Once the dependent and independent variables of the analysis were determined, a study of the normality of the different data populations was carried out using the ShapiroWilk test. Subsequently, the analysis of the data was conducted using the Mann-Whitney test [34]. Statistical significance was established at $p \leq 0.05$.

\section{Results}

\subsection{Enumeration of Microorganisms}

Microbiological analysis of the dry-cured sausages to monitor the dynamic changes in the populations responsible for the ripening was carried out. The results obtained from the enumeration of microorganisms of the six cases are shown in Table 1. Total aerobic microorganism counts showed average levels higher in the cases inoculated with L. sakei 205 $(\mathrm{B}, \mathrm{LI}+\mathrm{LAB}, \mathrm{HI}+\mathrm{LAB})$ than in the uninoculated control $(\mathrm{C})$ or in the cases only inoculated with L. monocytogenes (LI, HI). There was not an increase in the levels of the total aerobic microorganisms throughout the ripening of "salchichón" in any of the analyzed cases.

Initial Enterobacteriaceae counts ranged between 4.09 and $3.82 \log \mathrm{CFU} \mathrm{g}^{-1}$ in all analyzed cases (Table 1). However, the number of Enterobacteriaceae always significantly decreased $(p \leq 0.05)$ throughout the ripening and were below the detection limit at the end of the maturation process.

Counts on MSA agar (Staphylococci) showed initial levels of $\approx 5 \log \mathrm{CFU} \mathrm{g}^{-1}$ in C and B (Table 1). In both cases, an increase $(p \leq 0.05)$ in this microbial group of about $1 \log$ CFU g ${ }^{-1}$ was observed until day 30 of ripening. In C, such counts were kept constant until the end of the processing; however, in B, the levels of Staphylococci decreased until initial levels at the two last sampling days. Although in the cases where L. monocytogenes + L. sakei 205 were inoculated there were no data at days 0 and 15 of analysis, the evolution of Staphylococci at days 30,60 and 90 was similar to that the observed in case B, showing levels at the end of the ripening period of at least $1 \log \mathrm{CFU} / \mathrm{g}$ lower $(p \leq 0.05)$ than in the uninoculated control C. 
Table 1. Evolution of the different microbial groups in the different cases of dry-cured fermented sausages "salchichón" throughout the ripening process. Microorganisms determined in each media were: Total aerobic counts on plate count agar (PCA), Enterobacteriaceae on Violet Red Bile Glucose agar (VRBG), Staphylococci on Mannitol salt agar (MSA), and molds and yeasts on Malt extract agar (MEA).

\begin{tabular}{|c|c|c|c|c|c|c|}
\hline \multirow[b]{2}{*}{ Cases } & & \multicolumn{5}{|c|}{ Days of Ripening } \\
\hline & & 0 & 15 & 30 & 60 & 90 \\
\hline \multirow{4}{*}{$\mathrm{C}$} & PCA & $5.45 \pm 0.209^{c, 2}$ & $6.56 \pm 0.159^{a, 1}$ & $6.86 \pm 0.101^{a, 1}$ & $6.62 \pm 0.266^{b, 1}$ & $6.68 \pm 0.306^{a, b, 1}$ \\
\hline & VRBG & $4.01 \pm 0.153^{a, 1}$ & $3.48 \pm 0.360 \mathrm{~d}, 2$ & $2.11 \pm 0.312^{3}$ & $1.99 \pm 0.007^{\mathrm{a}, 3}$ & nd \\
\hline & MSA & $5.04 \pm 0.226^{2}$ & $5.94 \pm 0.217^{b, 1}$ & $6.08 \pm 0.077^{b, 1}$ & $6.02 \pm 0.161^{\mathrm{a}, 1}$ & $5.90 \pm 0.185^{\mathrm{a}, 1}$ \\
\hline & MEA & $5.32 \pm 0.281^{b, 3}$ & $6.38 \pm 0.188^{b, 1,2}$ & $6.68 \pm 0.074^{\mathrm{a}, \mathrm{b}, 1}$ & $6.66 \pm 0.158^{a, 1}$ & $6.24 \pm 0.100^{b, 2}$ \\
\hline \multirow{4}{*}{ B } & PCA & $6.98 \pm 0.135^{b, 1}$ & $6.43 \pm 0.328^{a, 2}$ & $6.43 \pm 0.328^{b, 2}$ & $6.89 \pm 0.170^{\mathrm{a}, \mathrm{b}, 1}$ & $7.10 \pm 0.118^{a, 1}$ \\
\hline & VRBG & $3.85 \pm 0.109^{a, b, 1}$ & $3.54 \pm 0.130^{c, d, 2}$ & $2.11 \pm 0.271^{3}$ & $1.97 \pm 0.012^{a, b, 3}$ & nd \\
\hline & MSA & $4.59 \pm 0.428^{2}$ & $6.33 \pm 0.074^{\mathrm{a}, 1}$ & $6.33 \pm 0.074^{\mathrm{a}, 1}$ & $5.08 \pm 0.397^{b, 2}$ & $5.05 \pm 0.208^{b, 2}$ \\
\hline & MEA & $7.16 \pm 0.083^{a, 1}$ & $7.04 \pm 0.151^{a, 1,2}$ & $6.92 \pm 0.097^{a, 1,2,3}$ & $6.70 \pm 0.209^{a, 3}$ & $6.81 \pm 0.092^{a, 2,3}$ \\
\hline \multirow{4}{*}{$\mathrm{LI}+\mathrm{LAB}$} & PCA & $7.10 \pm 0.049^{a, b, 1}$ & $6.20 \pm 0.068^{a, 3}$ & $6.20 \pm 0.068^{b, 3}$ & $6.75 \pm 0.281^{b, 2}$ & $6.54 \pm 0.199^{b, 2}$ \\
\hline & VRBG & $3.82 \pm 0.057^{b, 1}$ & $3.91 \pm 0.047^{b, 1}$ & $2.07 \pm 0.211^{2}$ & $1.97 \pm 0.007^{\mathrm{a}, \mathrm{b}, 2}$ & nd \\
\hline & MSA & - & - & $5.26 \pm 0.320^{\mathrm{e}, 1}$ & $4.99 \pm 0.243^{b, 1}$ & $4.50 \pm 0.225^{\mathrm{c}, 2}$ \\
\hline & MEA & - & - & $6.46 \pm 0.313^{b, c, 1}$ & $6.27 \pm 0.205^{b, 1,2}$ & $5.92 \pm 0.102 \mathrm{c}, 3$ \\
\hline \multirow{4}{*}{$\mathrm{HI}+\mathrm{LAB}$} & PCA & $7.36 \pm 0.212^{a, 1}$ & $6.46 \pm 0.084^{a, 2}$ & $6.46 \pm 0.084^{\mathrm{b}, 2}$ & $7.36 \pm 0.372^{a, 1}$ & $6.87 \pm 0.237^{\mathrm{a}, \mathrm{b}, 2}$ \\
\hline & VRBG & $4.09 \pm 0.215^{\mathrm{a}, 1}$ & $3.83 \pm 0.069^{b, c, 2}$ & $2.05 \pm 0.132^{3}$ & $1.98 \pm 0.014^{\mathrm{a}, \mathrm{b}, 3}$ & nd \\
\hline & MSA & - & - & $5.60 \pm 0.024^{d, 1}$ & $4.20 \pm 0.117^{c, 3}$ & $4.84 \pm 0.172^{b, c, 2}$ \\
\hline & MEA & - & - & $6.73 \pm 0.093^{a, b, 1}$ & $6.66 \pm 0.091^{a, 1}$ & $6.06 \pm 0.155^{b, c, 2}$ \\
\hline \multirow{4}{*}{ LI } & PCA & $5.19 \pm 0.251^{c, 3}$ & $5.29 \pm 0.327^{c, 2,3}$ & $5.82 \pm 0.245^{c, 1}$ & $5.72 \pm 0.256^{\mathrm{c}, 1,2}$ & $5.81 \pm 0.271^{c, 1}$ \\
\hline & VRBG & $3.84 \pm 0.246^{a, b, 2}$ & $4.28 \pm 0.139^{a, 1}$ & $<1.97 \pm 0.018^{3}$ & $<1.95 \pm 0.033^{b, 3}$ & nd \\
\hline & MSA & - & - & $5.42 \pm 1.120^{e, 1}$ & $3.66 \pm 0.335^{c, 3}$ & $4.83 \pm 0.094^{b, c, 2}$ \\
\hline & MEA & - & - & $5.38 \pm 0.267^{\mathrm{d}, 2}$ & $6.05 \pm 0.163^{b, 1}$ & $5.98 \pm 0.278^{b, c, 1}$ \\
\hline \multirow{4}{*}{$\mathrm{HI}$} & PCA & $6.47 \pm 0.010^{b, 1}$ & $5.75 \pm 0.118^{\mathrm{b}, 3}$ & $5.44 \pm 0.130^{\mathrm{d}, 4}$ & $6.10 \pm 0.089^{c, 2}$ & $5.95 \pm 0.219^{c, 2,3}$ \\
\hline & VRBG & $4.05 \pm 0.131^{\mathrm{a}, 1}$ & $3.98 \pm 0.167^{\mathrm{b}, 2}$ & $<2.18 \pm 0.212^{3}$ & $<1.98 \pm 0.005^{\mathrm{a}, \mathrm{b}, 3}$ & nd \\
\hline & MSA & - & - & $5.84 \pm 0.157^{c, 1}$ & $3.76 \pm 0.362^{c, 3}$ & $5.06 \pm 0.115^{b, 2}$ \\
\hline & MEA & - & - & $6.09 \pm 0.193^{c}$ & $6.02 \pm 0.135^{b}$ & $6.04 \pm 0.077^{b, c}$ \\
\hline
\end{tabular}

C (uninoculated control), B (inoculated with L. sakei), LI+LAB (inoculated with L. monocytogenes at $\approx 4 \log C$ FU g ${ }^{-1}$ combined with $L$. sakei), HI+LAB (inoculated with L. monocytogenes at $\approx 7 \log$ CFU g ${ }^{-1}$ combined with L. sakei), LI (inoculated with L. monocytogenes at $\approx 4 \log \mathrm{CFU} \mathrm{g}{ }^{-1}$ ), HI (inoculated with L. monocytogenes at $\approx 7 \log \mathrm{CFU} \mathrm{g}{ }^{-1}$ ). Values are expressed as mean \pm standard deviation. The means with different letters $(\mathrm{a}-\mathrm{e})$ in the same column indicate significant differences $(p \leq 0.05)$ between cases on the same day. Mean values with different numbers (1-4) in the same row indicate significant differences $(p \leq 0.05)$ between days in the same case and the same culture medium. nd: not detected (below the detection limit). (-): not determined.

Counts on MEA agar (molds and yeasts) ranged between 5.3 and $7.1 \log$ CFU/g during the ripening process in all the analyzed cases (Table 1). No significant effect of the ripening on levels of molds and yeasts was observed.

The LAB levels are shown in Figure 1. The microbiological analysis revealed significant differences at the beginning of the ripening between cases inoculated with $\mathrm{LAB}(\mathrm{B}, \mathrm{LI}+\mathrm{LAB}$, $\mathrm{HI}+\mathrm{LAB})$ and those which were not inoculated with LAB (C, LI, HI). Counts on MRS agar were around $7 \log \mathrm{CFU} \mathrm{g}{ }^{-1}$ for all cases inoculated with L. sakei (B, LI+LAB, HI+LAB) and 4-5 $\log$ CFU g ${ }^{-1}$ for those not inoculated with L. sakei (C, LI, HI). LAB counts of the cases inoculated with $L$. sakei remained constant $\left(\approx 7 \log \mathrm{CFU} \mathrm{g}{ }^{-1}\right)$ until 30 days of ripening, then they decreased slightly but their levels were always higher than $6 \log \mathrm{CFU} \mathrm{g}{ }^{-1}$. The levels of LAB in those cases that were not inoculated with L. sakei showed an increase in these counts at days 15 and 30 of ripening, reaching counts around $7 \log C F U ~ g^{-1}$ (Figure 1). Thereafter, counts decreased throughout the ripening process, except in $\mathrm{C}$, where the counts on MRS agar were more similar to those found in the cases inoculated with L. sakei 205. However, the cases inoculated only with L. monocytogenes (LI and HI) showed lower $\mathrm{LAB}$ counts throughout the maturation process, and were significantly different from the remaining cases at the end of the ripening. 


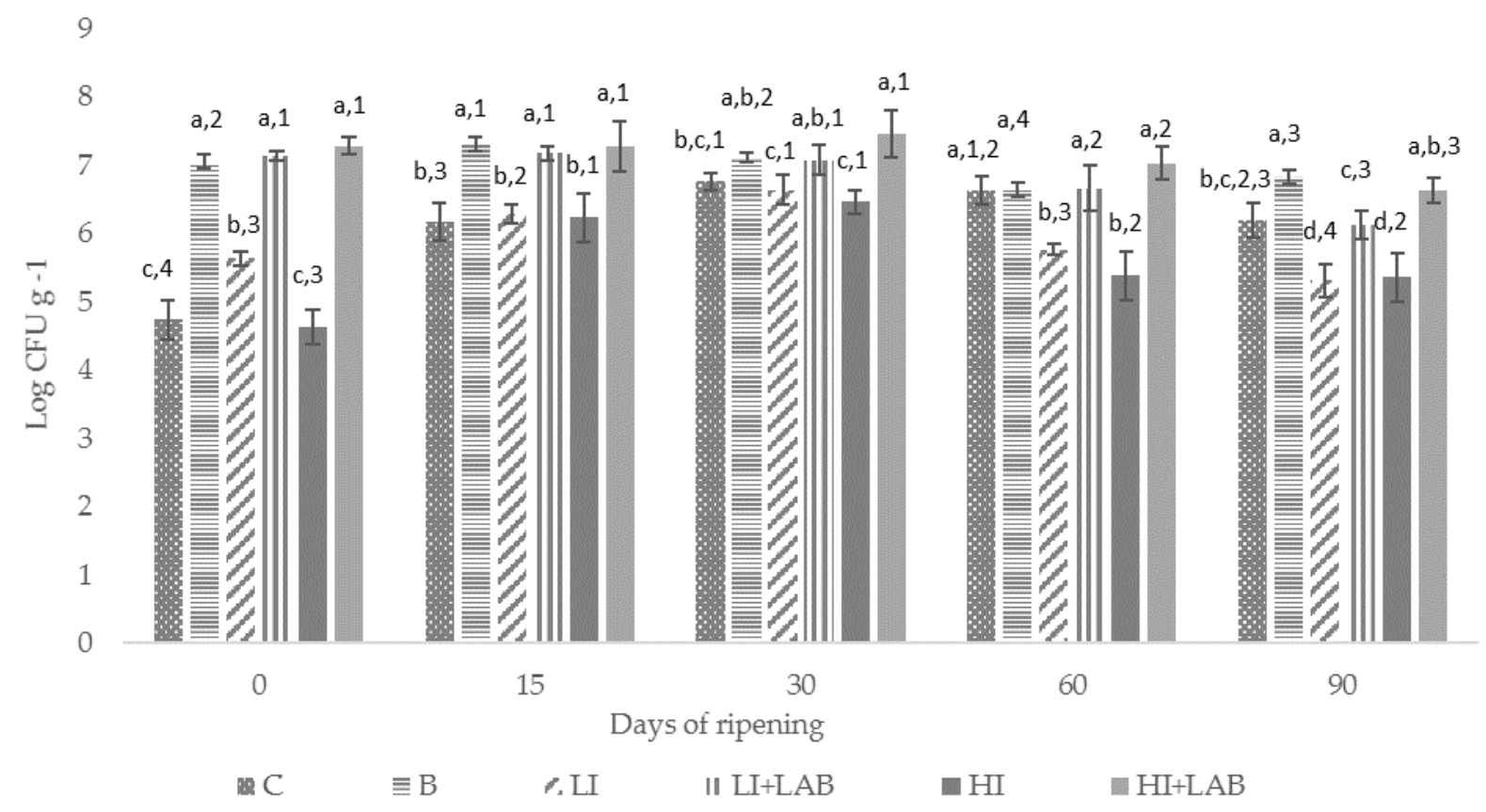

Figure 1. Evolution of lactic acid bacteria counts throughout the ripening process of "salchichón". C (uninoculated control), B (inoculated with L. sakei), LI+LAB (inoculated with L. monocytogenes at $\approx 4 \log$ CFU g ${ }^{-1}$ combined with L. sakei), HI+LAB (inoculated with L. monocytogenes at $\approx 7 \log$ CFU g ${ }^{-1}$ combined with L. sakei), LI (inoculated with L. monocytogenes at $\approx 4 \log \mathrm{CFU} \mathrm{g}{ }^{-1}$ ), HI (inoculated with L. monocytogenes at $\approx 7 \log \mathrm{CFU} \mathrm{g}{ }^{-1}$ ). Bars with different letters (a-d) indicate significant differences $(p \leq 0.05)$ between cases on the same day. Bars with different numbers (1-4) indicate significant differences $(p \leq 0.05)$ between days in the same case.

When isolates of the cases inoculated with $L$. sakei were analyzed to evaluate the implantation of this strain, most of the investigated isolates (85.7\%) were identified as $L$. sakei $(100 \%$ identity) by sequencing analysis of the $16 \mathrm{~S}$ rRNA region. In addition, these isolates showed the same pattern of L. sakei 205 in the PFGE analysis. The remaining strains were Lactobacillus plantarum group (7.15\%) and Lactobacillus curvatus (7.15\%). However, the isolates of C, LI and HI were identified as Lactobacillus curvatus (50\%), Enterococcus faecalis $(36 \%)$, and Lactobacillus plantarum groups (14\%).

The inoculation of $L$. monocytogenes resulted in an initial concentration of 6.63-6.60 $\log \mathrm{CFU} \mathrm{g}^{-1}$ in $\mathrm{HI}$ and HI+LAB and 4.09-4.18 CFU g ${ }^{-1}$ in $\mathrm{LI}$ and LI+LAB (Table 2). L. monocytogenes did not grow in any of the inoculated cases at any of the ripening time. Levels of this pathogenic bacterium showed significant $(p \leq 0.05)$ decreases in comparison with the initial ones, at day 15 (LI+BAL) and at days 30, 60 and 90 (all cases inoculated with L. monocytogenes; Table 2). After 90 days of ripening, the reduction in $L$. monocytogenes counts in LI was $1.61 \log \mathrm{CFU} \mathrm{g}{ }^{-1}$, while in LI+LAB it was significantly higher (2.03 $\log \mathrm{CFU} \mathrm{g}{ }^{-1}$, Figure 2). In HI, the reduction was $1.64 \log \mathrm{CFU} \mathrm{g}^{-1}$, while in $\mathrm{HI}+\mathrm{LAB}$ it was significantly higher $\left(1.77 \log \mathrm{CFU} \mathrm{g}{ }^{-1}\right.$, Figure 2$)$. 
Table 2. Evolution of L. monocytogenes counts on inoculated cases of dry-cured fermented sausages "salchichón" throughout the ripening process.

\begin{tabular}{cccccc}
\hline \multirow{2}{*}{ Cases } & \multicolumn{5}{c}{ Days of Ripening } \\
\cline { 2 - 6 } & $\mathbf{0}$ & $\mathbf{1 5}$ & $\mathbf{3 0}$ & $\mathbf{6 0}$ & $\mathbf{9 0}$ \\
\hline LI & $4.09 \pm 0.091^{1}$ & $3.68 \pm 0.451^{1,2}$ & $3.45 \pm 0.233^{2}$ & $2.89 \pm 0.136^{3}$ & $2.49 \pm 0.231^{\mathrm{b}, 3}$ \\
LI+LAB & $4.18 \pm 0.089^{1}$ & $3.84 \pm 0.103^{2}$ & $3.42 \pm 0.215^{3}$ & $2.74 \pm 0.117^{4}$ & $2.14 \pm 0.127^{\mathrm{a}, 5}$ \\
HI & $6.63 \pm 0.056^{1}$ & $6.43 \pm 0.179^{1,2}$ & $6.31 \pm 0.075^{\mathrm{b}, 2}$ & $5.12 \pm 0.214^{3}$ & $5.00 \pm 0.104^{\mathrm{b}, 3}$ \\
HI+LAB & $6.60 \pm 0.107^{1}$ & $6.43 \pm 0.136^{1}$ & $6.04 \pm 0.129^{\mathrm{a}, 2}$ & $4.99 \pm 0.111^{3}$ & $4.83 \pm 0.091^{\mathrm{a}, 3}$ \\
\hline
\end{tabular}

LI+LAB (inoculated with L. monocytogenes at $\approx 4 \log \mathrm{CFU} \mathrm{g}{ }^{-1}$ combined with L. sakei), HI+LAB (inoculated with L. monocytogenes at $\approx 7 \log$ CFU g ${ }^{-1}$ combined with $L$. sakei), LI (inoculated with $L$. monocytogenes at $\approx 4 \log C F U g^{-1}$ ), HI (inoculated with L. monocytogenes at $\left.\approx 7 \log \mathrm{CFU} \mathrm{g}{ }^{-1}\right)$. Values are expressed as mean \pm standard deviation. Mean values with different letters $(\mathrm{a}, \mathrm{b})$ in the same column indicate significant differences $(p \leq 0.05)$ between cases on the same incubation day. Mean values with different numbers $(1-4)$ in the same row indicates significant differences $(p \leq 0.05)$ between incubation days in the same case.

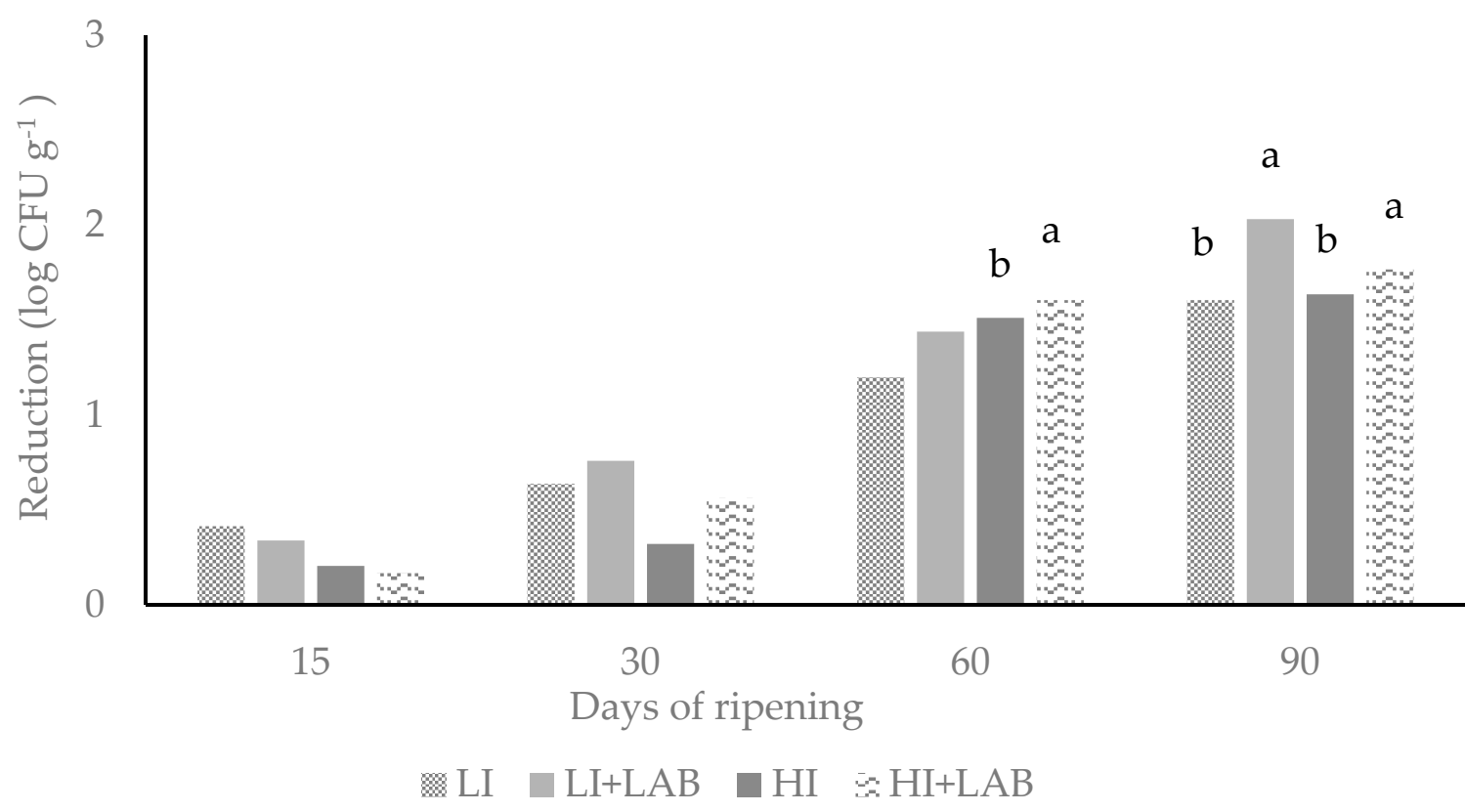

Figure 2. Reduction in the L. monocytogenes levels throughout the processing of dry-cured fermented "salchichón". LI (inoculated with L. monocytogenes at $\approx 4 \log \mathrm{CFU} \mathrm{g}{ }^{-1}$ ), LI+LAB (inoculated with L. monocytogenes at $\approx 4 \log \mathrm{CFU} \mathrm{g}^{-1}$ combined with $L$. sakei), $\mathrm{HI}$ (inoculated with L. monocytogenes at $\approx 7 \log \mathrm{CFU} \mathrm{g}{ }^{-1}$ ), HI+LAB (inoculated with L. monocytogenes at $\approx 7 \log$ CFU g ${ }^{-1}$ combined with L. sakei). Bars with different letters $(a, b)$ indicate significant differences $(p \leq 0.05)$ between cases on the same day.

\subsection{Physicochemical Parameters}

The evolution of moisture content (\%), $\mathrm{a}_{\mathrm{w}}$, and $\mathrm{pH}$ throughout the ripening process of cases C and B of "salchichón" is shown in Table 3. Initial moisture content in both cases was above $85 \%$, decreasing throughout the ripening process until values of $25-26 \%(p \leq 0.05$; Table 3). However, there were no significant differences $(p>0.05)$ between both cases at any of the ripening times. The $\mathrm{a}_{\mathrm{w}}$ decreased $(p \leq 0.05)$ from initial values $(0.946-0.947)$ found in the raw product to values below 0.790 at day 90 (Table 3). No significant differences $(p>0.05)$ among control and inoculated cases were observed in this parameter. 
Table 3. Moisture content, water activity $\left(\mathrm{a}_{\mathrm{w}}\right)$ and $\mathrm{pH}$ in uninoculated control (C) and case inoculated only with L. sakei 205 (case B) of dry-cured fermented sausages "salchichón" throughout the ripening process.

\begin{tabular}{|c|c|c|c|c|c|c|}
\hline & \multirow{2}{*}{ Cases } & \multicolumn{5}{|c|}{ Days of Ripening } \\
\hline & & 0 & 15 & 30 & 60 & 90 \\
\hline Moisture & $\mathrm{C}$ & $89.67 \pm 0.656^{1}$ & $56.35 \pm 2.525^{2}$ & $43.16 \pm 1.396^{3}$ & $32.34 \pm 2.155^{3,4}$ & $26.04 \pm 1.484^{4}$ \\
\hline content $(\%)$ & B & $85.84 \pm 0.235^{1}$ & $61.19 \pm 3.052^{2}$ & $42.70 \pm 1.387^{3}$ & $31.65 \pm 1.188^{4}$ & $25.17 \pm 1.484^{5}$ \\
\hline \multirow{2}{*}{$a_{w}$} & $\mathrm{C}$ & $0.947 \pm 0.001^{1}$ & $0.905 \pm 0.009^{2}$ & $0.874 \pm 0.003^{3}$ & $0.821 \pm 0.003^{4}$ & $0.785 \pm 0.008^{5}$ \\
\hline & $\mathrm{B}$ & $0.946 \pm 0001^{1}$ & $0.914 \pm 0.007^{2}$ & $0.877 \pm 0.005^{3}$ & $0.817 \pm 0.003^{4}$ & $0.779 \pm 0.010^{5}$ \\
\hline \multirow{2}{*}{$\mathrm{pH}$} & $\mathrm{C}$ & $5.83 \pm 0.226^{1,2}$ & $5.76 \pm 0.058^{a, 2}$ & $5.89 \pm 0.030^{a, 1,2}$ & $5.99 \pm 0.071^{1}$ & $5.87 \pm 0.105^{1,2}$ \\
\hline & B & $5.82 \pm 0.021^{1,2}$ & $5.48 \pm 0.058^{3}$ & $5.73 \pm 0.085^{2}$ & $5.98 \pm 0.050^{1}$ & $5.91 \pm 0.041^{1}$ \\
\hline
\end{tabular}

Values are expressed as mean \pm standard deviation. Mean values with different letters (a) in the same column indicate significant differences $(p \leq 0.05)$ between cases on the same day. Mean values with different numbers (1-4) in the same row indicate significant differences $(p \leq 0.05)$ between incubation days in the same case.

The evolution of $\mathrm{pH}$ differed between cases $\mathrm{C}$ and $\mathrm{B}$, showing lower values in the case inoculated with $L$. sakei than in the uninoculated control at days 15 and 30 of ripening (Table 3). However, at day 30, an increase in the $\mathrm{pH}$ value was observed in $\mathrm{C}$ up to values close to 5.9 , and they were kept constant until the end of ripening. There were no significant differences between both cases at days 60 and 90 of processing.

$\mathrm{NaCl}$ and nitrite contents were only determined in ripened "salchichón" (at day 90), showing both cases ( $\mathrm{C}$ and $\mathrm{B}$ ) with similar values, higher than $3.2 \% \mathrm{NaCl}$ and around 6.9-7.4 ppm of nitrite (Table 4$)$. No differences $(p>0.05)$ between both cases in these parameters were found.

Table 4. Sodium chloride $(\mathrm{NaCl})$ and nitrite contents in uninoculated control $(\mathrm{C})$ and case inoculated only with L. sakei 205 (B) in dry-cured fermented sausages "salchichón".

\begin{tabular}{ccc}
\hline Cases & $\mathbf{N a C l} \mathbf{~ ( \% )}$ & Nitrites (ppm) \\
\hline C & $3.29^{1} \pm 0.100$ & $7.49 \pm 1.019$ \\
B & $3.36 \pm 0.099$ & $6.96 \pm 0.770$ \\
\hline
\end{tabular}

${ }^{1}$ Values are expressed as mean \pm standard deviation. Mean values with different letters in the same column indicate significant differences $(p \leq 0.05)$ between cases.

\section{Discussion}

In this work, the survival and control of L. monocytogenes throughout the processing of dry-cured fermented sausage "salchichón" was evaluated by using the challenge test [27] For this study, an industrial traditional procedure for the production of "salchichón" was carried out [35]. Differences in the reduction/inactivation of L. monocytogenes in dry-cured fermented sausages in relation to the initial load have been reported [19,36]; therefore, two levels of inoculation of L. monocytogenes were used for this study: high level (about $7 \log \mathrm{CFU} \mathrm{g}{ }^{-1}$ ) and low level (around $4 \log \mathrm{CFU} \mathrm{g}{ }^{-1}$ ). In addition, exploring greater effectiveness in reducing L. monocytogenes, a selected strain of L. sakei (205) isolated from dry-cured fermented sausages and previously selected because of its antagonist activity against $L$. monocytogenes (unpublished data), was evaluated in the challenge test.

Physicochemical evaluation of case B inoculated with L. sakei 205 and uninoculated control (C) showed that the ripening process was correctly conducted. Thus, moisture content and $\mathrm{a}_{\mathrm{w}}$ decreased throughout the ripening process, from initial values around $85 \%$ to $25-26 \%$ and from 0.94 to $0.78 \mathrm{a}_{\mathrm{w}}$, respectively, reaching values similar to those usually reported for dry-cured fermented sausages [37-39]. The decrease in $a_{w}$ in drycured fermented sausages such as "salchichón" is important for extending the shelf life and safety of the product [40]. No differences for moisture content or $\mathrm{a}_{\mathrm{w}}$ parameters were observed between both cases. This evidences that $L$. sakei 205 does not provoke any modification in any of the two above-mentioned parameters, as has been reported for other LAB assayed [41,42]. However, the strain L. sakei 205 provoked a slight reduction 
in $\mathrm{pH}$ in the first 30 days of ripening, in comparison with uninoculated control, probably due to the increase in the lactic acid content, as a result of carbohydrate breakdown by microbial metabolism [43]. There was no reduction in $\mathrm{pH}$ in the uninoculated control (C), in spite of LAB counts from natural contamination reaching similar levels as those found in B (inoculated with L. sakei 205). In the last stages of processing, an increase in pH was detected, mainly in B (inoculated with L. sakei 205), which could be explained by the accumulation of non-protein nitrogen and amino acid catabolism products $[43,44]$. Consequently, no differences between $B$ and $C$ were detected for this parameter at day 90 of ripening. There were also no differences between both cases (B and $C)$ in the remaining physical-chemical parameters analyzed, $\mathrm{NaCl}$ and nitrite content. Levels of $\mathrm{NaCl}$ found at day 90 were similar to those reported for dry-cured fermented sausages [45] and in accordance with the level of salt used in the manufacture of sausages. Regarding nitrite content, low levels (lower than $10 \mathrm{ppm}$ ) were detected at the end ripening. Nitrite values obtained were in levels usually found in ripened sausages, because it is a very reactive compound and only residual nitrite that has not reacted with myoglobin is detected in finished products [46].

Besides the physicochemical parameter, the evolution of the different microbial groups in the six tested cases throughout the processing of "salchichón" was evaluated.

Levels of total aerobic microorganisms were higher in sausages inoculated with $L$. sakei 205 than in the remaining cases at the beginning of ripening, due to the effect of the addition of the protective cultures [22]. However, during processing there was not an increase in this microbiological parameter in any of the analyzed cases, mainly due to the decrease in the $\mathrm{a}_{\mathrm{w}}$ until values around 0.78 at the end of maturation but also by the slight decrease in $\mathrm{pH}$, and the presence of $\mathrm{NaCl}$ and nitrites. These data are consistent with those observed in other dry-cured fermented sausages [46-48].

LAB counts of the cases inoculated with L. sakei 205 remained constant, with values of about $7 \log$ CFU g ${ }^{-1}$ until 30 days of ripening and then a slight decrease was observed, probably due to the reduction in $\mathrm{a}_{\mathrm{w}}$, but counts were always higher than $6 \log \mathrm{CFU} \mathrm{g}^{-1}$. In addition, the characterization of the LAB isolates in these sausages showed that L. sakei 205 was the strain mostly detected, which means that this strain was properly implanted throughout the ripening. The levels of LAB in cases that were not inoculated with L. sakei 205 showed an increase in this microbial group at the beginning of processing to reach similar counts to those detected in the inoculated cases with the selected strain of LAB. However, in the analysis of the isolates no L. sakei was detected, which suggests that this strain only was present in cases inoculated with this selected LAB.

During the evolution of the remaining microbial groups, the decrease in Enterobacteriaceae counts until non-detectable levels at day 90 of ripening in all analyzed cases and the decrease in Staphylococci only in cases inoculated with L. sakei 205 at days 60 and 90 of ripening is relevant. The Enterobacteriaceae results are consistent with those reported by Cocolin et al. [49], who demonstrated the persistence of this microbial group until day 60 of ripening of dry-fermented sausages. It should be emphasized that no growth of Enterobacteriaceae during processing was found in this work; however, punctual growth of this microbial group during the processing of dry-cured fermented sausages has previously been reported $[46,50]$. The decrease in $\mathrm{a}_{\mathrm{w}}$, the various metabolites excreted by $\mathrm{LAB}$, and the slight drop in $\mathrm{pH}$ may partially explain the reduction and disappearance of Enterobacteriaceae in this kind of meat products [46]. The reduction in levels of Staphylococci only in cases inoculated with L. sakei 205 at the end of ripening may be related to the effect of the synergist action of this strain together with the reduction in $\mathrm{a}_{\mathrm{w}}$ throughout the processing.

The evaluation of the growth/inactivation rate of L. monocytogenes in both high and low inoculation levels showed no growth of this pathogen at any of the ripening times evaluated. This aspect is relevant because at the first 15 days of ripening there could be conditions of temperature $\left(7^{\circ} \mathrm{C}\right), \mathrm{a}_{\mathrm{w}}(0.947)$, and $\mathrm{pH}(5.8-5.4)$ which can favor the growth of $L$. monocytogenes, but the synergistic effect of the above parameters and the presence of 
$\mathrm{NaCl}$, nitrite, and $\mathrm{LAB}$ inoculated or from natural contamination inhibit the growth of this pathogen.

Throughout the ripening process, reductions in L. monocytogenes ranging from 1.6 to $2.2 \log$ CFU g ${ }^{-1}$ were observed at both high and low inoculation levels of "salchichón". These values are lower than reductions of up to $5 \log \mathrm{CFU} \mathrm{g}{ }^{-1}$ reported in inoculated Portuguese "linguiça" smoked dry-cured sausages [51], although in that work the reduction was mainly due to the smoking and the high temperatures employed in the process. However, reduction levels found in the present work are similar to those found for this pathogen in other dry-cured meat products [52]. Several authors have reported that a long ripening period, which is related to a high decrease in $\mathrm{a}_{\mathrm{w}}$, leads to a higher reduction in L. monocytogenes counts in dry-cured meat products [53-55]. However, short ripening periods in dry-cured fermented sausages have been associated with a greater survival of $L$. monocytogenes $[19,45]$. Nitrite used in the formulation of "salchichón" at a concentration lower than $150 \mathrm{ppm}$, as occurred in the present work, also contributes to the reduction in $L$. monocytogenes, as has been reported in different types of dry-fermented sausages [56,57].

There were no differences in reductions in relation to the level of inoculation of $L$. monocytogenes. However, the reduction in the pathogen counts was significantly higher in $\mathrm{HI}+\mathrm{LAB}$ and $\mathrm{LI}+\mathrm{LAB}$ than in $\mathrm{HI}$ and LI. This additional reduction provoked by the presence of $L$. sakei 205 was $0.42 \log C F U g^{-1}$ in LI. This proves that $L$. sakei 205 has anti-L. monocytogenes activity during the ripening of "salchichón", even considering that in the cases inoculated only with $L$. monocytogenes, indigenous LAB were found, probably with some antimicrobial effect. L. sakei is highly adapted to the fermented meat matrix [39], and many studies have determined that $L$. sakei has been widely used as a biocontrol for $L$. monocytogenes in dry fermented sausages [24,58].

Although the additional reduction in L. monocytogenes provoked by the selected $L$. sakei was not very high, it could be sufficient to guarantee the elimination of this pathogenic bacterium throughout the processing of "salchichón" when this pathogen contaminates this product at the usual levels (below $2 \log \mathrm{CFU} \mathrm{g}^{-1}$ ). This is very important, because minimizing the risk of listeriosis caused by the consumption of "salchichón" improves food safety and meets the microbiological criteria of RTE foods throughout their shelf life in the EU [1,2].

\section{Conclusions}

The processing of "salchichón" does not allow the growth of L. monocytogenes. On the contrary, it provokes a reduction in this pathogen that could be even higher by using the strain L. sakei 205 as a protective culture. The manufacturing of "salchichón" also allows minimization of Enterobacteriaceae until non-detectable levels. These findings may be of great interest both for the safety and extending the shelf-life of "salchichón".

Author Contributions: All the authors contributed significantly to the research. Conceptualization, J.J.C. and A.R.; data curation, I.M.; formal analysis, I.M., L.S.-M. and P.P.; funding acquisition, J.J.C.; methodology, I.M.; project administration, J.J.C.; resources, A.R. and J.J.C.; supervision, A.R. and J.J.C.; writing—original draft preparation, I.M. and J.J.C.; and writing—review and editing, I.M., A.R., L.S.-M., P.P. and J.J.C. All authors have read and agreed to the published version of the manuscript.

Funding: This work has been funded by the Spanish Ministry of Economy, Industry, and Competitiveness, the Spanish Ministry of Education, Culture and Sports and the Junta De Extremadura and Feder.

Data Availability Statement: Not applicable.

Acknowledgments: This work was supported by the INIA throughout the projects RTA-2017-00027C03-03 (Spanish Ministry of Economy, Industry, and Competitiveness) and the Junta de Extremadura and FEDER by IB16149, GR15108 and GR18056. I. Martín is supporting by a pre-doctoral fellowship from the Spanish Ministry of Education, Culture and Sports (FPU 16/05303).

Conflicts of Interest: The authors declare no conflict of interest. 


\section{References}

1. Peromingo, B.; Andrade, M.J.; Delgado, J.; Sánchez-Montero, L.; Núñez, F. Biocontrol of aflatoxigenic Aspergillus parasiticus by native Debaryomyces hansenii in dry-cured meat products. Food Microbiol. 2019, 82, 269-276. [CrossRef] [PubMed]

2. Bonilauri, P.; Merialdi, G.; Ramini, M.; Bardasi, L.; Taddei, R.; Grisenti, M.S.; Daminelli, P.; Cosciani-Cunico, E.; Dalzini, E.; Frustoli, M.A.; et al. Modeling the behavior of Listeria innocua in Italian salami during the production and high-pressure validation of processes for exportation to the U.S. Meat Sci. 2021, 172, 108315. [CrossRef] [PubMed]

3. Casquete, R.; Benito, M.J.; Martín, A.; Ruiz-Moyano, S.; Aranda, E.; Córdoba, M.G. Microbiological quality of salchichón and chorizo, traditional Iberian dry-fermented sausages from two different industries, inoculated with autochthonous starter cultures. Food Control 2012, 24, 191-198. [CrossRef]

4. Bernáldez, V.; Córdoba, J.J.; Rodríguez, M.; Cordero, M.; Polo, L.; Rodríguez, A. Effect of Penicillium nalgiovense as protective culture in processing of dry-fermented sausage "salchichón". Food Control 2013, 32, 69-76. [CrossRef]

5. Delgado, J.; Rondán, J.J.; Núñez, F.; Rodríguez, A. Influence of an industrial dry-fermented sausage processing on ochratoxin A production by Penicillium nordicum. Int. J. Food Microbiol. 2021, 339. [CrossRef] [PubMed]

6. Utrilla, M.C.; García Ruiz, A.; Soriano, A. Effect of partial replacement of pork meat with an olive oil organogel on the physicochemical and sensory quality of dry-ripened venison sausages. Meat Sci. 2014, 97, 575-582. [CrossRef]

7. Soriano, A.; Cruz, B.; Gómez, L.; Mariscal, C.; García Ruiz, A. Proteolysis, physicochemical characteristics and free fatty acid composition of dry sausages made with deer (Cervus elaphus) or wild boar (Sus scrofa) meat: A preliminary study. Food Chem. 2006, 96, 173-184. [CrossRef]

8. Schoder, D. Listeria: Listeriosis. Encycl. Food Health 2015, 561-566. [CrossRef]

9. Barmpalia-Davis, I.M.; Geornaras, I.; Kendall, P.A.; Sofos, J.N. Survival of Listeria monocytogenes in a Simulated Dynamic Gastrointestinal Model during Storage of Inoculated Bologna and Salami Slices in Vacuum Packages. J. Food Prot. 2008, 71, 2014-2023. [CrossRef]

10. Simpson, C.A.; Geornaras, I.; Yoon, Y.; Scanga, J.A.; Kendall, P.A.; Sofos, J.N. Effect of inoculum preparation procedure and storage time and temperature on the fate of Listeria monocytogenes on inoculated salami. J. Food Prot. 2008, 71, 494-501. [CrossRef]

11. Ferreira, V.; Barbosa, J.; Silva, J.; Felício, M.T.; Mena, C.; Hogg, T.; Gibbs, P.; Teixeira, P. Characterisation of alheiras, traditional sausages produced in the North of Portugal, with respect to their microbiological safety. Food Control 2007, 18, 436-440. [CrossRef]

12. Doménech, E.; Jimenez -Belenguer, A.; Amoros, J.A.; Ferrus, M.A.; Escriche, I. Prevalence and antimicrobial resistance of Listeria monocytogenes and Salmonella strains isolated in ready-to-eat foods in Eastern Spain. Food Control 2015, 47, 120-125. [CrossRef]

13. Meloni, D. Presence of Listeria monocytogenes in Mediterranean-Style Dry Fermented Sausages. Foods 2015, 4, 34-50. [CrossRef]

14. Schwartz, R.H.; Eaton, J.; Bower, B.D.; Aynsley-Green, A. Ketogenic Diets in the T Epilepsy: Short-Term Clinical E. Dev. Med. Child Neurol. 1989, 31, 149-151. [CrossRef]

15. Foodborne Ilness Outbreak Database Siena Foods Salame. Available online: http://www.outbreakdatabase.com/details/assimarket-pickles-2010/?vehicle=cucumber (accessed on 2 February 2021).

16. Commission, E. Commission Regulation (EC) N0. 2073/2005 of 15 November 2005 on microbiological criteria for foodstuffs. Off. J. Eur. Communitites 2005, 338, 1-26.

17. Commission, E. Commission Regulation (EC) No 1441/2007 of 5 December 2007 amending Regulation (EC) No 2073/2005 on microbiological criteria for foodstuff. Off. J. Eur. Communitites 2007, 322, $12-29$.

18. USDA-FSIS Salmonella Compliance Guidelines for Small and Very Small Meat and Poultry Establishments that Produce Ready-toEat (RTE) Products and Revised Appendix A. 2017; Volume 7. Available online: https://www.fsis.usda.gov/guidelines/2017-0008 (accessed on 3 February 2021).

19. Nightingale, K.K.; Thippareddi, H.; Phebus, R.K.; Marsden, J.L.; Nutsch, A.L. Validation of a traditional Italian-style salami manufacturing process for control of Salmonella and Listeria monocytogenes. J. Food Prot. 2006, 69, 794-800. [CrossRef]

20. Nissen, H.; Holck, A. Survival of Escherichia coli O157:H7, Listeria monocytogenes and Salmonella kentucky in Norwegian fermented, dry sausage. Food Microbiol. 1998, 15, 273-279. [CrossRef]

21. Cenci-Goga, B.T.; Rossitto, P.V.; Sechi, P.; Parmegiani, S.; Cambiotti, V.; Cullor, J.S. Effect of selected dairy starter cultures on microbiological, chemical and sensory characteristics of swine and venison (Dama dama) nitrite-free dry-cured sausages. Meat Sci. 2012, 90, 599-606. [CrossRef] [PubMed]

22. Pedonese, F.; Torracca, B.; Mancini, S.; Pisano, S.; Turchi, B.; Cerri, D.; Nuvoloni, R. Effect of a Lactobacillus sakei and Staphylococcus xylosus protective culture on Listeria monocytogenes growth and quality traits of Italian fresh sausage (salsiccia) stored at abusive temperature. Ital. J. Anim. Sci. 2020, 19, 1363-1374. [CrossRef]

23. Chaillou, S.; Champomier-Vergès, M.C.; Cornet, M.; Crutz-Le Coq, A.M.; Dudez, A.M.; Martin, V.; Beaufils, S.; Darbon-Rongère, E.; Bossy, R.; Loux, V.; et al. The complete genome sequence of the meat-borne lactic acid bacterium Lactobacillus sakei 23K. Nat. Biotechnol. 2005, 23, 1527-1533. [CrossRef]

24. Zagorec, M.; Champomier-Vergès, M.-C. Lactobacillus sakei: A Starter for Sausage Fermentation, a Protective Culture for Meat Products. Microorganisms 2017, 5, 56. [CrossRef]

25. Gelinski, J.M.L.N.; Baratto, C.M.; Casagrande, M.; de Oliveira, T.P.; Megiolaro, F.; de Martini Soares, F.A.S.; de Souza, E.M.B.; Vicente, V.A.; Fonseca, G.G. Control of pathogens in fresh pork sausage by inclusion of Lactobacillus sakei BAS0117. Can. J. Microbiol. 2019, 65, 831-841. [CrossRef] 
26. García, C.; Martín, A.; Timón, M.L.; Córdoba, J.J. Microbial populations and volatile compounds in the "bone taint" spoilage of dry cured ham. Lett. Appl. Microbiol. 2000, 30, 61-66. [CrossRef]

27. Beaufort, A.; Cornu, M.; Bergis, H.; Lardeux, A.L.; Lombard, B. EURL Lm Technical Guiadance Document for Conducing Shelf-Life Studies on Listeria monocytogenes in Ready to Eat Foods. Available online: http:/ /www.fsai.ie/uploadedFiles/EURL\% 0ALm_TechnicalGuidanceDocument\%0ALmshelf-lifestudies_V3_2014-\%0A06-06(2).pdf (accessed on 24 January 2021).

28. ISO 11290-2: Método Horizontal para el Recuento de L. monocytogenes y Listeria spp.; International Organization for Standardization: Geneva, Switzerland, 2017.

29. Walter, J.; Tannock, G.W.; Tilsala-Timisjarvi, A.; Rodtong, S.; Loach, D.M.; Munro, K.; Alatossava, T. Detection and identification of gastrointestinal Lactobacillus species by using denaturing gradient gel electrophoresis and species-specific PCR primers. Appl. Environ. Microbiol. 2000, 66, 297-303. [CrossRef]

30. Alía, A.; Andrade, M.J.; Rodríguez, A.; Martín, I.; Pérez-Baltar, A.; Medina, M.; Córdoba, J.J. Prevalence and characterization of Listeria monocytogenes in deboning and slicing areas of Spanish dry-cured ham processing. LWT Food Sci. Technol. 2020, 128, 109498. [CrossRef]

31. AOAC. Moisture in Malt Gravimetric Method (935.29), 17th ed.; AOAC: Gaithersburg, MD, USA, 2000.

32. AOAC. Official Methods of Analysis of AOAC International, 20th ed.; AOAC: Gaithersburg, MD, USA, 2016; Volume 52, ISBN 0935584870 .

33. AOAC. Official Methods of Analysis of AOAC International, 18th ed.; AOAC: Gaithersburg, MD, USA, 2005 ; Volume 3172.

34. Mann, H.B.; Whitney, D. On a test of whether one of two random variables is stochastically larger than the other. Ann. Math. Stat. 1974, 2, 347-370. [CrossRef]

35. Delgado, J.; Peromingo, B.; Rodríguez, A.; Rodríguez, M. Biocontrol of Penicillium griseofulvum to reduce cyclopiazonic acid contamination in dry-fermented sausages. Int. J. Food Microbiol. 2019, 293, 1-6. [CrossRef] [PubMed]

36. Thévenot, D.; Delignette-Muller, M.L.; Christieans, S.; Vernozy-Rozand, C. Fate of Listeria monocytogenes in experimentally contaminated French sausages. Int. J. Food Microbiol. 2005, 101, 189-200. [CrossRef] [PubMed]

37. Casquete, R.; Benito, M.J.; Martín, A.; Ruiz-Moyano, S.; Hernández, A.; Córdoba, M.G. Effect of autochthonous starter cultures in the production of "salchichón", a traditional Iberian dry-fermented sausage, with different ripening processes. LWT Food Sci. Technol. 2011, 44, 1562-1571. [CrossRef]

38. Álvarez, M.; Andrade, M.J.; García, C.; Rondán, J.J.; Núñez, F. Effects of preservative agents on quality attributes of dry-cured fermented sausages. Foods 2020, 9, 1505. [CrossRef]

39. El Adab, S.; Essid, I.; Hassouna, M. Microbiological, biochemical and textural characteristics of a tunisian dry fermented poultry meat sausage inoculated with selected starter cultures. J. Food Saf. 2015, 35, 75-85. [CrossRef]

40. Chevallier, I.; Ammor, S.; Laguet, A.; Labayle, S.; Castanet, V.; Dufour, E.; Talon, R. Microbial ecology of a small-scale facility producing traditional dry sausage. Food Control 2006, 17, 446-453. [CrossRef]

41. Najjari, A.; Boumaiza, M.; Jaballah, S.; Boudabous, A.; Ouzari, H.I. Application of isolated Lactobacillus sakei and Staphylococcus xylosus strains as a probiotic starter culture during the industrial manufacture of Tunisian dry-fermented sausages. Food Sci. Nutr. 2020, 8, 4172-4184. [CrossRef] [PubMed]

42. Pavli, F.G.; Argyri, A.A.; Chorianopoulos, N.G.; Nychas, G.J.E.; Tassou, C.C. Effect of Lactobacillus plantarum L125 strain with probiotic potential on physicochemical, microbiological and sensorial characteristics of dry-fermented sausages. LWT 2020, 118 . [CrossRef]

43. Aleson-Carbonell, L.; Fernández-López, J.; Pérez-Alvarez, J.A.; Kuri, V. Functional and sensory effects of fibre-rich ingredients on breakfast fresh sausages manufacture. Food Sci. Technol. Int. 2005, 11, 89-97. [CrossRef]

44. Pérez-Alvarez, J.A.; Sayas-Barberá, M.E.; Fernández-López, J.; Aranda-Catalá, V. Physicochemical characteristics of Spanish-type dry-cured sausage. Food Res. Int. 1999, 32, 599-607. [CrossRef]

45. Gonzales-Barron, U.; Cadavez, V.; Pereira, A.P.; Gomes, A.; Araújo, J.P.; Saavedra, M.J.; Estevinho, L.; Butler, F.; Pires, P.; Dias, T. Relating physicochemical and microbiological safety indicators during processing of linguiça, a Portuguese traditional dry-fermented sausage. Food Res. Int. 2015, 78, 50-61. [CrossRef]

46. Fernández-López, J.; Sendra, E.; Sayas-Barberá, E.; Navarro, C.; Pérez-Alvarez, J.A. Physico-chemical and microbiological profiles of "salchichón" (Spanish dry-fermented sausage) enriched with orange fiber. Meat Sci. 2008, 80, 410-417. [CrossRef]

47. Capita, R.; Llorente-Marigómez, S.; Prieto, M.; Alonso-Calleja, C. Microbiological profiles, pH, and titratable acidity of chorizo and salchichón (Two Spanish dry fermented sausages) manufactured with ostrich, deer, or pork meat. J. Food Prot. 2006, 69, 1183-1189. [CrossRef]

48. Metaxopoulos, J.; Samelis, J.; Papadelli, M. Technological and microbiological evaluation of traditional processes as modified for the industrial manufacturing of dry fermented sausage in Greece. Ital. J. Food Sci. 2001, 13, 3-18.

49. Cocolin, L.; Dolci, P.; Rantsiou, K.; Urso, R.; Cantoni, C.; Comi, G. Lactic acid bacteria ecology of three traditional fermented sausages produced in the North of Italy as determined by molecular methods. Meat Sci. 2009, 82, 125-132. [CrossRef] [PubMed]

50. Lizaso, G.; Chasco, J.; Beriain, M.J. Microbiological and biochemical changes during ripening of salchichon, a Spanish dry cured sausage. Food Microbiol. 1999, 16, 219-228. [CrossRef]

51. Hajmeer, M.N.; Tajkarimi, M.; Gomez, E.L.; Lim, N.; O’Hara, M.; Riemann, H.P.; Cliver, D.O. Thermal death of bacterial pathogens in linguiça smoking. Food Control 2011, 22, 668-672. [CrossRef] 
52. Taddei, R.; Giacometti, F.; Bardasi, L.; Bonilauri, P.; Ramini, M.; Fontana, M.C.; Bassi, P.; Castagnini, S.; Ceredi, F.; Pelliconi, M.F.; et al. Effect of production process and high-pressure processing on viability of Listeria innocua in traditional Italian dry-cured coppa. Ital. J. Food Saf. 2020, 9, 104-109. [CrossRef]

53. Reynolds, A.E.; Harrison, M.A.; Rose-Morrow, R.; Lyon, C.E. Validation of dry cured ham process for control of pathogens. J. Food Sci. 2001, 66, 1373-1379. [CrossRef]

54. Montiel, R.; Peirotén, Á.; Ortiz, S.; Bravo, D.; Gaya, P.; Martínez-Suárez, J.V.; Tapiador, J.; Nuñez, M.; Medina, M. Inactivation of Listeria monocytogenes during dry-cured ham processing. Int. J. Food Microbiol. 2020, 318, 108469. [CrossRef]

55. Barbuti, S.; Grisenti, M.S.; Frustoli, M.A.; Parolari, G. Validation of the Manufacturing Process of Italian Dry-Cured Ham(Prosciiutto) for the Inactivation of Listeria monocytogenes and Salmonella spp. Int. Congr. Meat Sci. Technol. 2009, PE6.10, 361.

56. Sebranek, J.G. Natural and organic cured meat products: Regulatory, manufacturing, marketing, quality and safety issues. Am. Meat Sci. Assoc. 2007, 1, 1-15.

57. Lücke, F.K. Utilization of microbes to process and preserve meat. Meat Sci. 2000, 56, 105-115. [CrossRef]

58. Bošković, M.; Tadić, V.; Dordević, J.; Glišić, M.; Lakićević, B.; Dimitrijević, M.; Ž Baltić, M. Effect of starter cultures on survival of Listeria monocytogenes in Čajna sausage. IOP Conf. Ser. Earth Environ. Sci. 2017, 85, 012074. [CrossRef] 